\title{
Is a skill intensity reversal a mere theoretical curiosum? Evidence from the U.S. and Mexico
}

\author{
Yoshinori Kurokawa* \\ University of Tsukuba \\ May 9, 2011 \\ (Published in Economics Letters, 112 (2011), 151-154.)
}

\begin{abstract}
A rising skill premium in two countries can be explained by the HeckscherOhlin model assuming a "skill intensity reversal." This assumption, however, poses an empirical challenge since past research has found little evidence for the so-called "factor intensity reversal." We now show clear-cut evidence for the existence of a skill intensity reversal.
\end{abstract}

Keywords: Heckscher-Ohlin model; Skill intensity reversal; Wage inequality; Electronics products

JEL classification: F11; F14; F16

*Tel.\&fax: +81-29-853-7426. E-mail address: kurokawa@dpipe.tsukuba.ac.jp. I am very grateful to Timothy Kehoe for his invaluable guidance and to Cristina Arellano, Michele Boldrin, and Terry Roe for their helpful advice. I am also grateful to Winston Chang, Taiji Furusawa, Koichi Hamada, Katsuhito Iwai, Liaoliao Li, Michihiro Ohyama, Yoshimasa Shirai, the editor, and an anonymous referee for their detailed comments and suggestions. I wish to thank seminar participants at the Trade and Development Workshop at Minnesota, Keio, SUNY-Buffalo, the MVEA 44th Annual Meeting, the MEA 72nd Annual Meeting, the Spring 2008 Midwest International Economics Meetings, and the 2009 JEA Annual Fall Meeting for their useful comments. I also thank Andrew Cassey, Kirsten Jamsen, and Kim Strain for their careful correction of my English, and Daniel Chiquiar and Gordon Hanson for their help with Mexican data. However, the remaining errors are exclusively mine. 


\section{Introduction}

One of the interesting facts about the U.S. and Mexican economies is that, as in Table 1 , both countries showed a rise in the relative wage of high-skilled to low-skilled workers in manufacturing industries from 1994 to 2000. ${ }^{1}$ Table 1 also shows that U.S.-Mexican trade as a percent of GDP increased in each country during the same period. ${ }^{2}$ Hence, this increased trade might have contributed to the recent increase in skill premium in these countries. ${ }^{3}$

At first sight, this seems to pose a serious theoretical challenge to us. This is because the standard Heckscher-Ohlin (H-O) model predicts that the relative wage of high-skilled to low-skilled workers should increase in the high-skill abundant U.S. but decrease in low-skill abundant Mexico after trade liberalization. ${ }^{4}$

This, however, is merely an apparent theoretical challenge. In fact, as also documented by Reshef (2007), the rising skill premium in these two countries can be explained simply by the static two-good H-O model if we assume a "skill intensity reversal." 5 That is, U.S. exports to Mexico of goods which are relatively high-skill intensive compared to other goods within the U.S. but relatively low-skill intensive within Mexico will increase demand for U.S. high-skilled workers but decrease demand for Mexican low-skilled workers. On the other hand, U.S. imports from Mexico of goods which are relatively low-skill intensive within the U.S. but relatively high-skill intensive within Mexico will decrease demand for U.S. low-skilled workers but increase demand for Mexican high-skilled workers. Thus the relative wage of high-skilled to

\footnotetext{
${ }^{1}$ As will be discussed in Section 3.1, here we use non-production and production workers as an index for high-skilled and low-skilled workers. We calculate the relative wages based on the U.S. Annual Survey of Manufactures (ASM) and the Mexican Monthly Industrial Survey (Encuesta Industrial Mensual, or EIM). The EIM data exclude maquiladora employment and otherwise represent all of Mexican manufacturing (Robertson, 2006).

${ }^{2}$ Here, trade is the sum of U.S. exports to and U.S. imports from Mexico, and the data for trade and GDP are from the International Trade Administration and the Bureau of Economic Analysis.

${ }^{3}$ As will be shown later, our interest is in a static story, so here we look at a one-time increase in the skill premium comparing 1994 and 2000. The time-series movements of the skill premium during the period 1994-2000 are thus outside the scope of this paper. Note, however, that the EIM shows that the Mexican skill premium increased between 1994 and 1996, and since then, it has become stable (Esquivel and Rodríguez-López, 2003). Robertson (2004) argues, using the Mexican Industrial Census, that it declined from 1994 to 1998.

${ }^{4}$ In fact, past trade studies have provided non-H-O-based explanations for the rise in skill premium in the two countries. For example, see Feenstra and Hanson (1996), Dinopoulos and Segerstrom (1999), Acemoglu (2003), Sayek and Sener (2006), and Kurokawa (2011). See Feenstra and Hanson (2003) and Kremer and Maskin (2006) for a survey on trade and inequality.

${ }^{5}$ Reshef (2007) shows, using simulations, that tariff reductions can largely increase the skill premium under the existence of skill intensity reversals.
} 


\begin{tabular}{lcccc}
\hline TABLE 1 & \multicolumn{4}{l}{} \\
\begin{tabular}{l} 
U.S. and Mexican Skill Premium and U.S.-Mexican Trade, 1994 and 2000 \\
\hline Year
\end{tabular} & $\begin{array}{c}\text { U.S. } \\
\text { Skill Premium }\end{array}$ & $\begin{array}{c}\text { Mex. } \\
\text { Skill Premium }\end{array}$ & $\begin{array}{c}\text { U.S.-Mex. Trade } \\
\text { /U.S. GDP }\end{array}$ & $\begin{array}{c}\text { U.S.-Mex. Trade } \\
\text { /Mex. GDP }\end{array}$ \\
\hline 1994 & 1.78 & 2.89 & $1.42 \%$ & $23.85 \%$ \\
2000 & 1.91 & 2.95 & $2.52 \%$ & $42.58 \%$ \\
\hline
\end{tabular}

low-skilled workers will increase in both countries. ${ }^{6}$

A serious empirical challenge is, however, imposed on us. This is because little evidence for the so-called "factor intensity reversal" has been found in manufacturing industries in past empirical studies (Leontief, 1964; Ball, 1966; Moroney, 1967), thus supporting Samuelson's (1951-1952) impression that a factor intensity reversal has much less empirical importance than theoretical interest. ${ }^{7}$

Should we thus conclude that a factor intensity reversal is theoretically interesting but empirically unimportant? The answer is no. This is because the so-called factor intensity reversal has so far referred only to a capital/labor intensity reversal. However, our focus is now on a skill intensity reversal. Unfortunately, no serious empirical work on skill intensity reversal has been done until now although a division of factors by skills has recently become more and more important in international trade theories. Thus it is time to revive the factor intensity reversal controversy of the 1960s with the fresh viewpoint of a skill division among labor.

This paper now provides clear-cut empirical evidence for the existence of a skill intensity reversal. We first show that both the U.S. net exports to Mexico of electronics products and the U.S. net imports from Mexico of non-electronics products significantly increased from 1994 to 2000.

We next show that the electronics products were relatively high-skill intensive compared to the non-electronics products within the U.S. but relatively low-skill intensive within Mexico both in 1994 and in 2000. Here, let us recall that, as Table 1 has shown, the skill premium also increased in both countries. All of the above evidence is compatible with the static two-good H-O story with the reversal of relative skill intensities.

\footnotetext{
${ }^{6}$ Of course, all industries in the U.S. might use skilled labor more intensively than do the corresponding industries in Mexico, but it is the reversal of relative skill intensities that the H-O theory says can account for the increase in the wage gap in both countries. Thus, in the following discussion, the word "skill intensity reversal" refers to the reversal of relative skill intensities between the two countries.

${ }^{7}$ Maize (corn) production is frequently cited as an example of the factor intensity reversal between the U.S. and Mexico in terms of capital and labor. If maize is relatively labor intensive in Mexico but relatively capital intensive in the U.S., Mexican imports of maize from the U.S. would hurt labor in both countries (Larudee, 1998).
} 


\section{Evidence for U.S.-Mexican Trade}

First, let us identify the industry which accounts for the major U.S. net exports to Mexico. It is the electronics industry, which is here defined by the 2-digit SITC (revision 3) category 77.

Figure 1(a) shows the U.S. net exports of the electronics products to Mexico in 1994 and 2000. As can be seen, they remarkably increased from 1994 to 2000 . In fact, as shown in Table 2, it is in 2000 that the U.S. electronics industry became the largest net export industry to Mexico of all the 2-digit SITC categories of U.S. manufacturing industries. Next, let us define all the other 2-digit SITC categories of U.S. manufacturing industries as the non-electronics industry. Figure 1(b) shows the U.S. net exports of the non-electronics products to Mexico in 1994 and 2000. As can be seen, they remarkably decreased from 1994 to 2000. In other words, the U.S. net imports of the non-electronics products from Mexico significantly increased from 1994 to 2000. The data for Figures 1(a) and 1(b) and Table 2 are from the International Trade Administration.

Thus, in the following main text, we divide the manufacturing industries into the electronics industry, whose U.S. net exports increased from 1994 to 2000, and the non-electronics industry, whose U.S. net imports increased during the same period.

\section{Evidence for Skill Intensity Reversal}

\subsection{Definition of Skill Intensity}

Let us define skill intensity for manufacturing industry $i$ by ${ }^{8}$

$$
\frac{\mathrm{NPD}_{i}}{\mathrm{PD}_{i}}=\frac{\text { The Number of Non-Production Workers in Industry } i}{\text { The Number of Production Workers in Industry } i}
$$

Here, we have used non-production and production workers as an index for highskilled and low-skilled workers. This classification is made in the ASM and the EIM, and it is used as an index for the skill level for workers in many papers. Feenstra and Hanson (1996), for example, use the classification for both U.S. and Mexican skills as well as does our paper.

In fact, there is evidence for the U.S. which exhibits that this non-production and production classification works well as a division of the labor force by skill (Berman

\footnotetext{
${ }^{8}$ Here, the number of workers in an industry is aggregated (not a weighted average) across firms in the industry.
} 


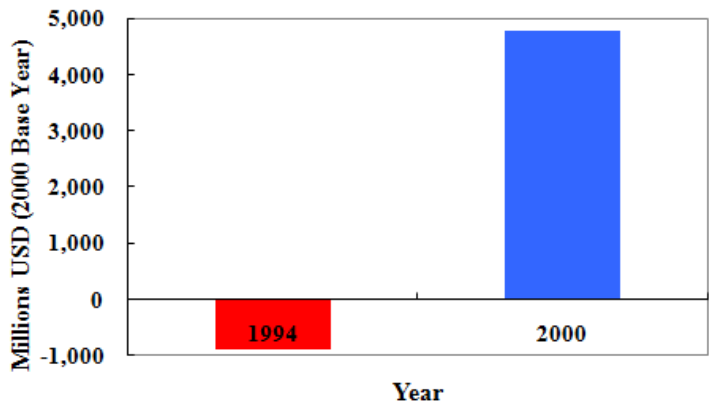

(a) Electronics

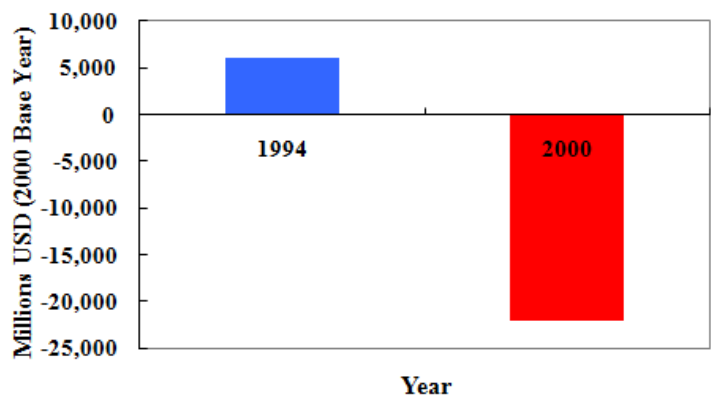

(b) Non-Electronics

\section{FIGURE 1. U.S. Net Exports of Electronics and Non-Electronics}

Products to Mexico, 1994 and 2000

TABLE 2
Top 5 U.S. Net Exports to Mexico in Manufacturing Industries, 2000
\begin{tabular}{cccc} 
\\
Rank & SITC Code & Description & Millions USD \\
\hline 1 & 77 & Electrical Machinery, Apparatus \& Appliances & 4,764 \\
2 & 99 & Low Value Shipments & 4,446 \\
3 & 89 & Miscellaneous Manufactured Articles & 2,837 \\
4 & 65 & Textile Yarn, Fabrics & 2,254 \\
5 & 57 & Plastics in Primary Form & 2,156 \\
\hline
\end{tabular}

et al., 1994; Sachs and Shatz, 1994; Berman et al., 1998). There is also evidence for Mexico. Robertson (2004) shows that production workers have less education in every industry than non-production workers and that industries with higher relative employment ratios of non-production to production workers also have higher average education levels. Hanson and Harrison (1999) argue that there are no data for Mexico that provide a more detailed breakdown of employment by skill and by industry.

Thus using the non-production/production classification to classify skill intensity seems valid in both the U.S. and Mexico, albeit imperfectly.

\subsection{Skill Intensity Reversal between the U.S. and Mexico}

Figures 2(a) and 2(b) plot the skill intensities of the electronics and non-electronics industries in the U.S. and Mexico in 1994 and 2000. The broken lines represent the 
averages of skill intensity within each country. Here, we define the 2-digit SIC 1987 category 36 and the 3 -digit ISIC (revision 2) category 383 as the U.S. and Mexican electronics industries, respectively. These approximately correspond to the 2-digit SITC (revision 3) category 77 used in Section 2. ${ }^{9}$ The data for Figures 2(a) and 2(b) are from the ASM and the EIM. ${ }^{10}$

If an industry in the U.S. and Mexico showed a similarity in relative skill intensity, then the industry's skill intensity would be located in the first or third quadrants in these figures. That is, this industry would be relatively high-skill intensive compared to the other industry within each country or relatively low-skill intensive within each country.

However, the electronics industry actually exhibited a skill intensity reversal both in 1994 and in 2000. As can be seen, the industry's skill intensity is located in the second quadrant in these figures. That is, this electronics industry was relatively highskill intensive compared to the non-electronics industry within the U.S. but relatively low-skill intensive within Mexico.

On the other hand, the non-electronics industry also exhibited a skill intensity reversal both in 1994 and in 2000. As can be seen, the industry's skill intensity is located in the fourth quadrant in these figures. That is, this non-electronics industry was relatively low-skill intensive within the U.S. but relatively high-skill intensive within Mexico.

It is worth noting that the skill intensity reversal in the electronics industry displayed in these figures is compatible with the structure of technologies in Feenstra and Hanson $(1996,1999)$, whereby the low-skill abundant country specializes in the low-skill intensive operations within a given industry, and similarly the high-skill abundant country specializes in the high-skill intensive operations.

Note also that it can be shown that the skill intensity for the electronics product industry was located in the first quadrant in 1987. This indicates that this industry was relatively high-skill intensive within each country and thus there was no skill intensity reversal in the late 1980s.

\footnotetext{
${ }^{9}$ Haveman's Industry Concordances (http://www.macalester.edu/research/economics/PAGE/HA VEMAN/Trade.Resources/TradeConcordances.html), now maintained by Robertson, provides many correspondence tables between the major classification systems.

${ }^{10}$ Note that Figures 2(a) and 2(b) use different scales, since here we want to emphasize the relative relationship between the skill intensities of the two industries which determines a comparative advantage in the $\mathrm{H}-\mathrm{O}$ model. The absolute values of the skill intensities are not of interest in this paper.
} 


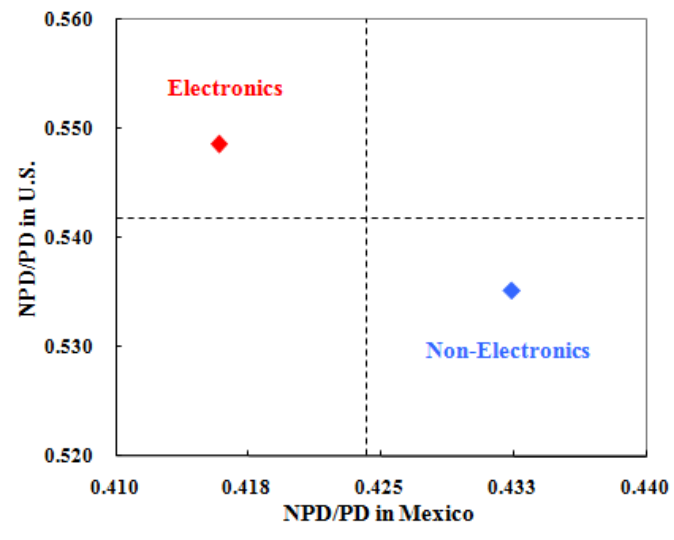

(a) 1994

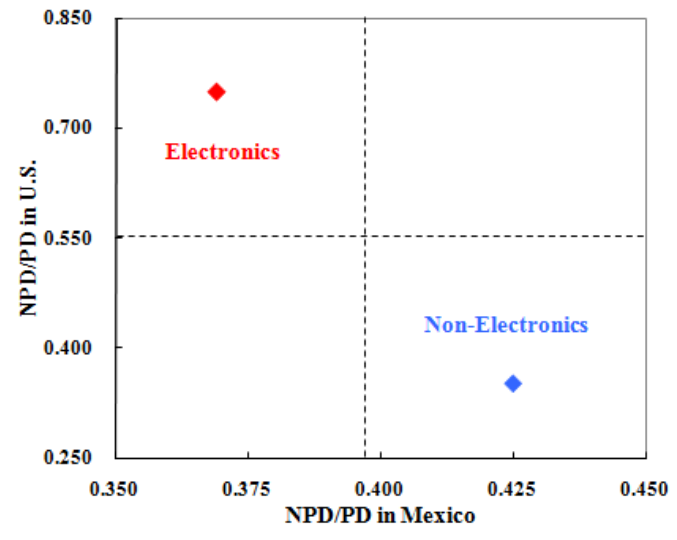

(b) 2000

FIGURE 2. Skill Intensity in U.S. and Mexico, 1994 and 2000

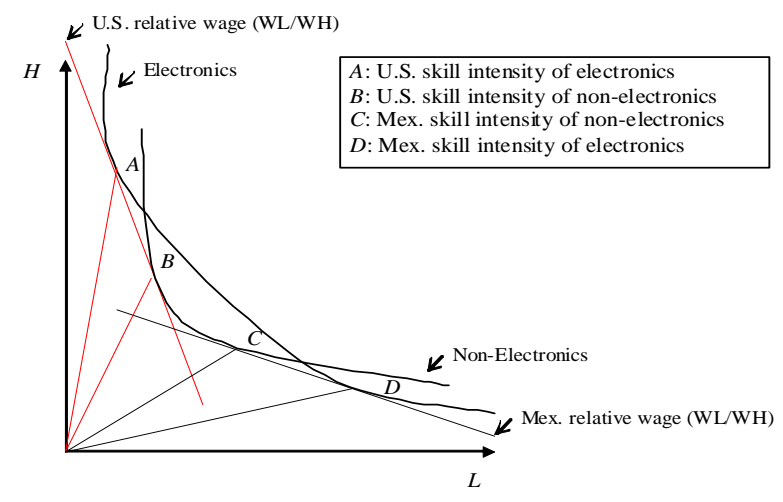

\section{FIGURE 3. Isoquant Curves of Electronics and Non-Electronics}

\section{Conclusion and Next Steps}

We have shown that the U.S. net exports to Mexico of the electronics products, which were relatively high-skill intensive compared to the non-electronics products within the U.S. but relatively low-skill intensive within Mexico, significantly increased from 1994 to 2000. The skill premium also increased in both countries. Thus all of the above evidence is compatible with the static two-good H-O story with the reversal of relative skill intensities. In fact, trade in electronics products, one of the largest product categories in U.S.-Mexican trade, is a significant example of a skill intensity reversal between the U.S. and Mexico. 
Of course, several next steps could be taken for future research. First, this paper has provided motivational evidence for a further empirical analysis. Thus a next logical step is to formally test the relationship between trade, skill intensity reversals, and skill premium. ${ }^{11}$

Second, as shown in Figure 3, a skill intensity reversal is theoretically possible only when the isoquant curves of the export and import sectors have more than one intersection. This in turn depends on whether these two sectors have different elasticities of substitution between skills. Since we have presented in this paper solid empirical evidence that a skill intensity reversal actually exists, a next logical step is to return to the fundamentals - to investigate the technological structures of the U.S. and Mexico and estimate their elasticities of substitution between skills.

Third, our purpose has been to show evidence compatible with the two-good H-O model, so here we have used very aggregated data. It would also be interesting to look at very disaggregated data and investigate the skill intensities of various disaggregated goods.

Finally, this paper has been focusing on the discrepancy between the standard H-O model and the data after the North American Free Trade Agreement (NAFTA), showing a possible resolution on the basis of a skill intensity reversal. Note, however, that the skill premium in the U.S. and Mexico actually began to rise in the late 1980s, when we could not observe any clear-cut skill intensity reversal. Kurokawa (2011), for example, has successfully eliminated the discrepancy between the model and the data before the NAFTA without assuming this skill intensity reversal. A next step is, thus, to connect these pre- and post-NAFTA studies. ${ }^{12}$

\section{References}

Acemoglu, D., 2003. Patterns of skill premia. Review of Economic Studies 70, 199-230.

Ball, D.S., 1966. Factor-intensity reversals in international comparison of factor costs and factor use. Journal of Political Economy 74, 77-80.

Berman, E., Bound, J., Griliches, Z., 1994. Changes in the demand for skilled labor

\footnotetext{
${ }^{11}$ There are papers which empirically estimate the effects of trade on skill premium. For example, see Feenstra and Hanson (1996).

${ }^{12}$ A possible argument is that after the NAFTA, the skill intensity reversal (though it might not be the main factor) reinforced the increase in skill premium that was originally caused by factors other than the skill intensity reversal before the NAFTA.
} 
within U.S. manufacturing: evidence from the Annual Survey of Manufactures. Quarterly Journal of Economics 109, 367-397.

Berman, E., Bound, J., Machin, S., 1998. Implications of skill-biased technological change: international evidence. Quarterly Journal of Economics 113, 1245-1279.

Dinopoulos, E., Segerstrom, P., 1999. A Schumpeterian model of protection and relative wages. American Economic Review 89, 450-472.

Esquivel, G., Rodríguez-López, J.A., 2003. Technology, trade, and wage inequality in Mexico before and after NAFTA. Journal of Development Economics 72, 543-565.

Feenstra, R.C., Hanson, G.H., 1996. Foreign investment, outsourcing and relative wages. In: Feenstra, R.C., Grossman, G.M., Irwin, D.A. (Eds.), The Political Economy of Trade Policy: Papers in Honor of Jagdish Bhagwati. MIT Press, Cambridge, MA, pp. 89-127.

Feenstra, R.C., Hanson, G.H., 1999. The impact of outsourcing and high-technology capital on wages: estimates for the United States, 1979-1990. Quarterly Journal of Economics 114, 907-940.

Feenstra, R.C., Hanson, G.H., 2003. Global production sharing and rising inequality: a survey of trade and wages. In: Choi, E.K., Harrigan, J. (Eds.), Handbook of International Trade. Basil Blackwell, Oxford, pp. 146-187.

Hanson, G.H., Harrison, A., 1999. Trade liberalization and wage inequality in Mexico. Industrial and Labor Relations Review 52, 271-288.

Kremer, M., Maskin, E., 2006. Globalization and inequality. Working Paper, Department of Economics, Harvard University.

Kurokawa, Y., 2011. Variety-skill complementarity: a simple resolution of the tradewage inequality anomaly. Economic Theory 46, 297-325.

Larudee, M., 1998. Integration and income distribution under the North American Free Trade Agreement: the experience of Mexico. In: Baker, D., Epstein, G., Pollin, R. (Eds.), Globalization and Progressive Economic Policy. Cambridge University Press, Cambridge, UK, pp. 273-295.

Leontief, W., 1964. An international comparison of factor costs and factor use: a review article. American Economic Review 54, 335-345. 
Moroney, J.R., 1967. The strong-factor-intensity hypothesis: a multisectoral test. Journal of Political Economy 75, 241-249.

Reshef, A., 2007. Heckscher-Ohlin and the global increase of skill premia: factor intensity reversals to the rescue. Working Paper, Department of Economics, New York University.

Robertson, R., 2004. Relative prices and wage inequality: evidence from Mexico. Journal of International Economics 64, 387-409.

Robertson, R., 2006. Globalization and Mexican labor markets. Proceedings, Federal Reserve Bank of Dallas, 61-80.

Sachs, J.D., Shatz, H.J., 1994. Trade and jobs in U.S. manufacturing. Brookings Papers on Economic Activity, 1-84.

Samuelson, P.A., 1951-1952. A comment on factor price equalisation. Review of Economic Studies 19, 121-122.

Sayek, S., Sener, M.F., 2006. Outsourcing and wage inequality in a dynamic product cycle model. Review of Development Economics 10, 1-19. 